\title{
Molecular characterization of the Anopheles maculipennis complex in the Islamic Republic of Iran
}

M.A. Oshaghi, ${ }^{1}$ M.M. Sedaghat ${ }^{1}$ and H. Vatandoost ${ }^{1}$

$$
\begin{aligned}
& \text { تحديد الصفات المزيئية لمعقَّدات الأنوفيلات المبقَّعة في منطقَتِّن من جمهورية إيران الإسلامية }
\end{aligned}
$$

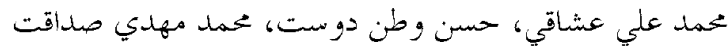

المخلاحسة: استُخدمت المقايسة التشخيصية بالتفاعل السلسلي للبوليميراز PCR باستخدام بادئات مناوعة للأنواع

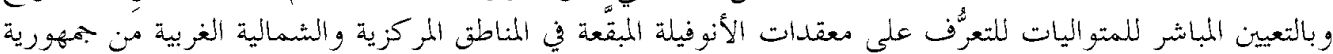

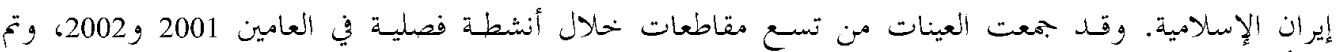

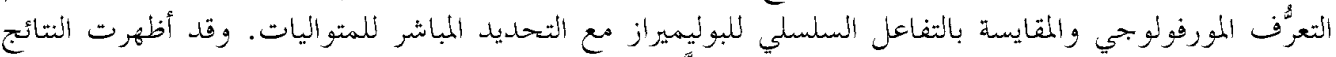

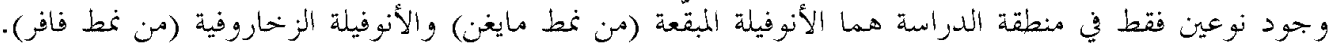

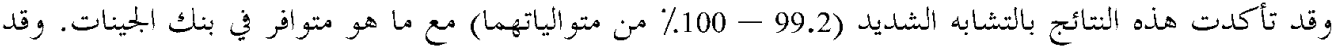

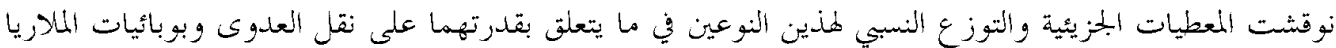
في المنطقة.

ABSTRACT A diagnostic polymerase chain reaction (PCR) assay using species-specific primers and direct sequencing was used to identify members of the Anopheles maculipennis complex in the north-west and central regions of the Islamic Republic of Iran. Specimens were collected from 9 provinces during 2 seasonal activities in 2001-2002, identified morphologically and subjected to PCR assay and direct sequencing. Results showed that only 2 species, An. maculipennis Meigen, and An. sacharovi Faver, were present in the area of study. This was confirmed by the high similarity $(99.2 \%-100 \%)$ of their sequences with those available in GenBank. The molecular data and relative distribution of these species in relation to their vectorial capacity and the epidemiology of malaria in the region are discussed.

Caractérisation moléculaire du complexe Anopheles maculipennis dans deux régions de la République islamique d'Iran

RESUME Une PCR (amplification en chaîne par polymérase) diagnostique avec des amorces spécifiques d'espèces et un séquençage direct ont été utilisés pour la détermination des membres du complexe Anopheles maculipennis dans les régions du nord-ouest et du centre de la République islamique d'Iran. Des spécimens ont été capturés dans 9 provinces pendant deux activités saisonnières en 2001-2002, identifiés morphologiquement et soumis à une PCR et à un séquençage direct. Les résultats ont montré que seulement 2 espèces, An. maculipennis Meigen et An. sacharovi Faver, étaient présentes dans la zone d'étude. Cela a été confirmé par la forte similarité $(99,2-100 \%)$ de leurs séquences avec celles disponibles dans la GenBank. Les données moléculaires et la répartition relative de ces espèces par rapport à leur capacité vectorielle et l'épidémiologie du paludisme dans la région sont examinées.

${ }^{1}$ Department of Medical Entomology and Vector Control, School of Public Health and Institute of Health Research, Tehran University of Medical Sciences, Tehran, Islamic Republic of Iran.

المجلة الصحية لشرق المتوسط، منظمة الصحة العالمية، المجلد التاسع، العدد ع، ب... 


\section{Introduction}

Mosquitoes of the Anopheles maculipennis complex have been incriminated as some of the main malaria vectors in Europe and the Middle East [1] and also in northern and central areas of the Islamic Republic of Iran [2]. The current situation of this taxon shows that there are 8 Palaearctic members within the complex: An. atroparvus Van Thiel, An. beklemishevi Stegnii \& Kabanova, An. labranchiae Falleroni, An. maculipennis Meigen, An. martinius Shingarev, An. melanoon (as subalpinus) Hackett, An. messeae Falleroni, and An. sacharovi Favre [1]. These are closely related species and morphologically indistinguishable. Distinctive differences between them have been identified in mating patterns [3], inversion polymorphism in the polytene chromosomes of the larval salivary gland [1], and DNA sequences [4-6]. Generally, the 8 species occupy disjunctive geographic regions, although several do overlap in distribution. Of the 8, only 3, An. labranchiae, An. atroparvus, and An. sacharovi are important malaria vectors throughout their ranges.

Previous reports concerning members of the An. maculipennis complex in the Islamic Republic of Iran were based on morphological characteristics of eggs and recorded the presence of 5 members of the complex: An. maculipennis, An sacharovi, An. melanoon, An. messeae, and An. subalpinus [7-9]. Saebi has shown that $A n$. maculipennis sensu lato is distributed in different north, west and central provinces of the country, including West and East Azarbijan, Kurdistan, Kermanshahan, Hamadan, Gilan, Mazanderan, Golestan, Khorasan, Semnan, Tehran, Markazi, Esfahan, Chahar-Mahal-Bakhtiary, Fars, Lorestan, and Kohkiluyeh Boyer-Ahmad provinces [10]. That study, however, did not determine which sibling species of the complex are present in those provinces, and since then no further studies have been carried out to determine current distribution.

Although malaria has been eradicated from northern and central regions of the country, because of major ecological and social changes such as increased travel to and from the south-east corner of the country and neighbouring countries, where malaria is endemic, there is a high risk of reintroduction in these regions. Since the 5 reported species in the Islamic Republic of Iran are capable of transmitting malaria $[2,11,12]$, and because of the high risk of the resurgence of malaria transmission in the region, correct vector identification is essential to assess the potential risk of malaria, and to advise on appropriate control and monitoring strategies.

In our study we used the previously developed diagnostic polymerase chain reaction (PCR) system [6] that can differentiate between six members of the complex: $A n$. maculipennis sensu stricto, An sacharovi, An. messeae, An. melanoon, An. atroparvus and An. labranchiae. The speciesspecific primers were designed based on differences in the nucleotide sequences in internal transcribed spacer regions (ITS2) of the ribosomal DNA that in combination with a universal primer could generate amplification products of different lengths, each unique for 1 species. In addition, DNA sequences of the ITS2 region were generated and the sequences compared with the ITS2 sequences in GenBank to confirm the results of species-specific PCR assays.

\section{Methods}

Mosquito collection was carried out in 9 provinces located in the semi-arid and

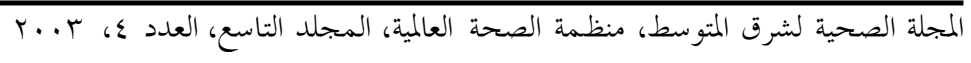


mountainous regions of north-west and central parts of the Islamic Republic of Iran: West Azarbijan, Kermanshahan, Zanjan, Tehran, Esfahan, Chahar-Mahal-Bakhtiary, Fars, Markazi, and Kohkiluyeh Boyer-Ahmad. Based on area and previous data on the distribution of species in each province, 2-5 villages were selected for sample collection. Sample collections were performed during two seasons, Octoberearly December 2001 and June-early October 2002. To cover different ecological and biological factors, different techniques were used to collect adult mosquitoes from indoors and outdoors of stables and houses, and on human and animal baits. Individual, blood-fed, live females were transported into cups to lay eggs. Eggs were reared in insectaries to produce larvae. All the breeding places were also checked for larvae. Morphological investigation was performed to identify specimens using standard keys for larvae and adults of the Anopheles species of the Islamic Republic of Iran [13].

DNA was extracted from specimens following the phenol-chloroform extraction protocol [14]. The pellet was suspended in $100 \mathrm{~mL}$ TE buffer or double distilled water; 1-2 mL of suspended DNA was used in each PCR reaction. Amplification of ITS2 was carried out using the 5.8SF and 28SR primers of Collins and Paskewitz [15]. Diagnostic PCR assays were carried out using 5.8SF as the universal forward primer and 6 species-specific primers as reverse primers (Table 1). We carried out PCR using a thermocycler (Mastercycler, Eppendorf, Hamburg, Germany) and the reaction parameters described by Proft et al. [6]. Sequence data were obtained following PCR purification with the QIAgen PCR purification kit, and cycle sequencing reactions were read on an ABI 377 automated sequencer (PE Applied Biosystems). Following sequencing, the template DNA was dried and retained at $-70^{\circ} \mathrm{C}$ for future reference. Sequences were edited and aligned using Sequencher version 3.1.1 and Clustal $X$ [16] software packages. Similarity with other sequences in GenBank was assessed using FASTA search (http://www.ebi.ac. uk/fasta33/).

\section{Results}

The diagnostic PCR and sequencing results showed that only 2 species of the An. maculipennis complex, An. maculipennis s.s.

\begin{tabular}{lccc}
\hline \multicolumn{4}{l}{ Table 1 Characteristics of universal and species-specific primers used in this study } \\
\hline Primer & Code & Nucleotide sequence (5' $\mathbf{~} \mathbf{3}^{\prime}$ ) & Length of PCR product (bp) \\
\hline Universal forward & 5.8S-UN & TGTGAACTGCAGGACACATG & 494 (sacharovi) \\
Universal reverse & 28S-UN & ATGCTTAAATTAGGGGGTA & 472 (maculipennis) \\
An. sacharovi & ASA & CAAGAGATGGATGTTTTACG & 180 \\
An. maculipennis & AMA & TATTTGAGGCCCATGGGCTA & 410 \\
An. atroparvus & AAT & CGTTTGGCTTGGGTTATGA & 117 \\
An. labranchiae & ALA & GTATCTCTGCTGCTATGGTC & 374 \\
An. melanoon & AML & TGCAAGTTGAAACCTGGGGC & 224 \\
An. messeae & AMS & GACGCCTCACGATGACCTT & 305
\end{tabular}

المجلة الصحية لشرق المتوسط، منظمة الصحة العالمية، المجلد التاسع، العدد ع، ب... 
and An. sacharovi, are present in the northwest and central parts of the Islamic Republic of Iran. The size of specific PCR products for An. maculipennis s.s. was 410 bp and for An. sacharovi 180 bp (Figure 1). Geographic distribution of these species in different provinces is as follows: in West Azarbijan and Zanjan provinces, which are more mountainous, both are present. The prevalence of An. sacharovi was $80 \%$ and $40 \%$ in these provinces respectively. In Tehran, Isfahan, Chahar-Mahal-Bakhtiary and Kohkiluyeh Boyer-Ahmad provinces we found only An. maculipennis s.s. and in Fars province only An. sacharovi. None of the An. maculipennis sibling species were found in Kermanshahan and Markazi provinces. In addition to An. maculipennis s.l., other anopheline species which were found in the area of study were An. superpictus, An. multicolour, An. pulcherimus, An. apoci, An. sergenti, An. turkudi, An. claviger and An. dthali.

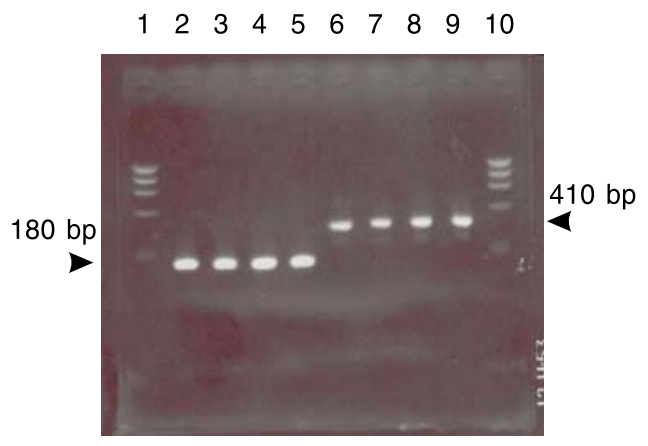

Line 1 and 10 molecular weight marker, lines 2-5: An. sacharovi and lines 6-9: An maculipennis s.s. The lengths of the polymerase chain reaction products are 410 bp for An. maculipennis s.s. and 180 bp for An. sacharovi.

Figure 1 Specific polymerase chain reaction products for An. sacharovi and An. maculipennis s.s.
The rDNA-ITS2 region of both species was amplified successfully and was subjected to sequencing. We generated DNA sequences for 26 specimens from the north-west and central regions, An. тасиlipennis s.s. (20 specimens) and An. sacharovi (6 specimens). Inclusive of primers (43 bp), the ITS2 fragment lengths were 472 and 494 nucleotides for An. maculipennis s.s. and An. sacharovi respectively. The AT content was $49.36 \%$ in An. maculipennis s.s. and $52.23 \%$ in An. sacharovi. Total sequence divergence between the species, including indels, was $26.37 \%$. The 24 bp length difference is accounted for by 10 indel events within the ITS2 region, at bases 149-152 (4 bp), 170-171 (2 bp), 189 (1 bp), 209-212 (4 bp), 224 (1 bp), 238(1 bp), 255(1 bp), 375 (1 bp), 403-405 (3 bp), 443-448 (6 bp) (Figure 2). In addition to the indels, 67 species-specific base substitutions were noted, of which 29 (43.3\%) were transitions and 38 (56.7\%) were transversions. No intraspecific variation was observed in either length or nucleotide composition of the fragments in all samples sequenced, and hence, each species shared the same haplotypes. Comparison of the sequence data with available ITS2 sequences in GenBank showed that An. sacharovi sequences share $100 \%$ similarity with entry Z83198 [4] and 99.35\% similarity with entry of AF436062 of Djadid (unpublished data). The AF436062 is erroneously identified An. maculipennis, it is in fact An. sacharovi [5]. A similar situation was found for the An. maculipennis s.s. sequences in that they share $100 \%$ similarity with AF455820, AF342714, AF342713, AF342715, and 99.788\% similarity with Z50104, 99.364\% similarity with AF455819, and 99.153\% similarity with AF455818 [4,5].

Sequences generated in this study have been submitted in GenBank under the following accession numbers: AY114205,

المجلة الصحية لشرق المتوسط، منظمة الصحة العالمية، المجلد التاسع، العدد ؟، ب... 


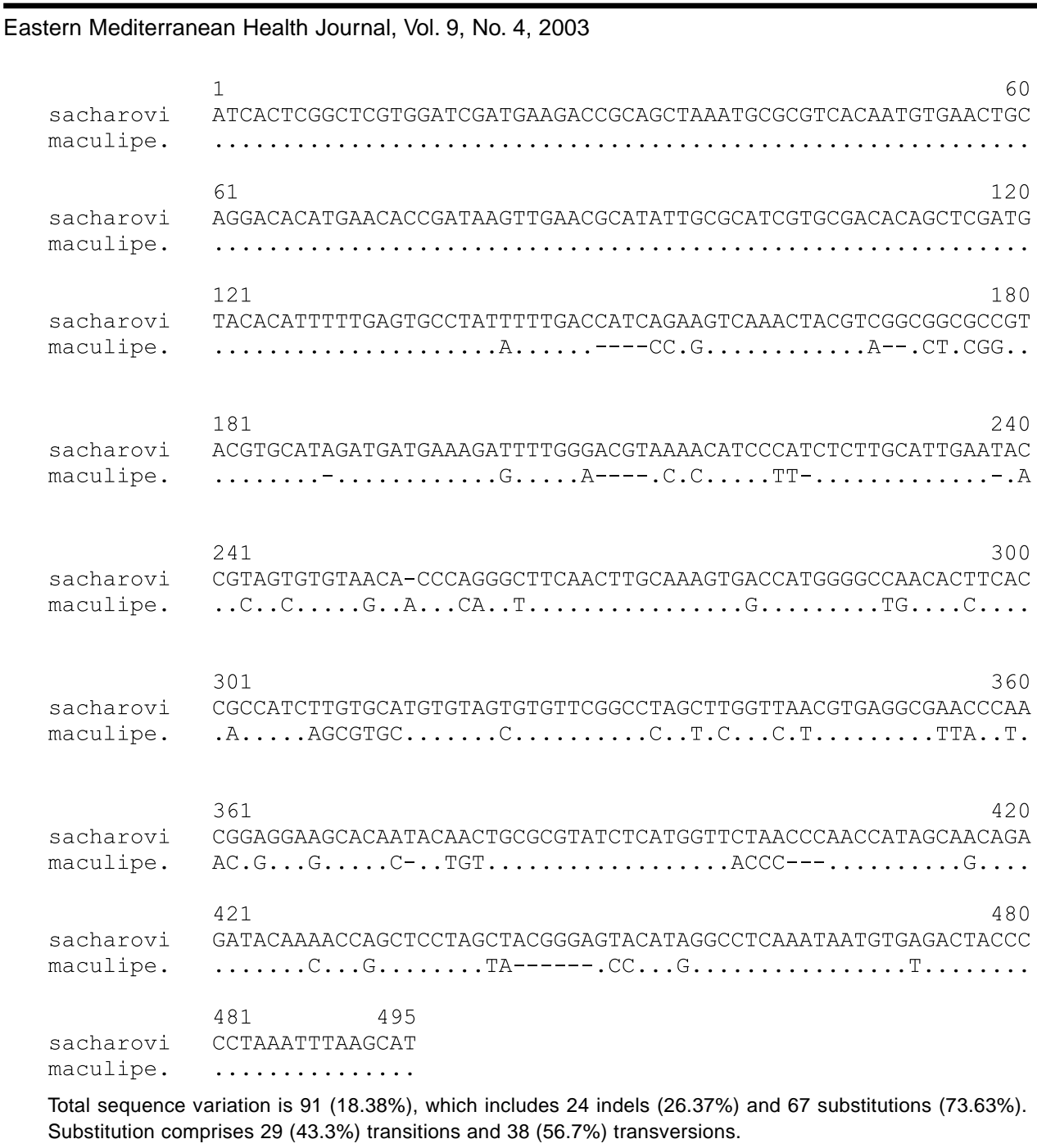

Figure 2 Alignment of internal transcribed spacer 2 nucleotide sequences of An. maculipennis s.s. and An. sacharovi generated in this study

\begin{abstract}
AY114206, AY114207, AY114209, AY114210, and AY114211 for An. sacharovi and AF536337, AY137789, AY137792, AY137793, AY137794, AY137799, AY137800, AY137801, AY137805, AY137806, AY137807, AY137808, AY137809, AY137810, AY137811, AY137812, AY137813, AY137814, AY137815, AY137816 for An. maculipennis s.s.
\end{abstract}

\section{Discussion}

In this study, using the PCR assay and sequence data, we have found that only 2 members of the complex An. sacharovi and An. maculipennis s.s. exist in the northwest and central regions of the Islamic Republic of Iran. This is the first record based on both molecular and morphological tools

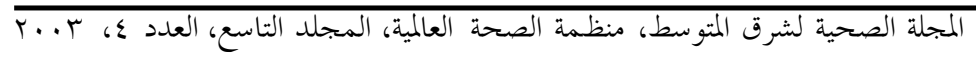


concerning the distribution of these species in the area of study, and is concordant with the results of Dow who reported 2 members of the complex, An. maculipennis s.s. and $A n$. sacharovi, in the north-west and the central plateau [7].

The AT content for An. maculipennis s.s. and An. sacharovi (49.36\% and $52.23 \%$ respectively) is in concordance with the $40 \%-50 \%$ AT values reported for other mosquitoes of the subgenus Anopheles, including members of the maculipennis and quadrimaculatus groups [4-6,17].

Identification of mosquito complex species based on PCR has proven to be an appropriate methodology. It is easy to apply in practice, works on all developmental stages of both sexes, and only small amounts of tissue are needed, which facilitates further extensive studies on the same specimens. In this study, since we had only An. sacharovi and An. maculipennis species, the species-specific primers were tested in the presence of just 2 DNA species. However, none of the other 4 species-specific primers in the PCR tube produced amplicons, therefore, we conclude that PCR assay is a reliable tool for identification of at least 2 sibling species of the An. maculipennis complex in the Islamic Republic of Iran.

Among the An. maculipennis sibling species, An. sacharovi is regarded as the most distinct member of the complex and morphologically distinguishable [18]. Based on morphological characteristics, early studies [10,19-21] demonstrated the presence of An. sacharovi in Tehran, Isfahan, Kohkiluyeh Boyer-Ahmad, and Chahar-Mahal-Bakhtiary provinces, and An. maculipennis s.l. in Kermanshahan and Markazi provinces. However, in our study we found no trace of them in these provinces. This could be due to sample size, insecticide application, improved mosquito control measures, or the huge climatic, so- cioeconomic and agricultural changes which have occurred over the past few decades in the regions of the study.

The presence of 2 important malaria vectors (An. sacharovi and An. maculipennis) of the maculipennis group, and the presence of other important malaria vectors such as An. superpictus, An. pulcherimus, and An. dthali in the area of study is particularly important for the epidemiology of malaria and vector control programmes in the region. Although malaria has been eradicated from north-west and central regions of the country, recently there have been some reports of an increase in malaria cases in the north-west [22]. Combining these facts with major ecological and social changes such as the increased parasite pool resulting from travel to and from the southeast corner of the country and neighbouring countries where malaria is endemic, the reintroduction of malaria in these regions becomes a realistic possibility, and health authorities should use appropriate control or monitoring strategies.

\section{Acknowledgements}

This investigation received technical and financial support from the joint WHO Eastern Mediterranean Region (EMRO), Division of Communicable Diseases (DCD) and the WHO Special Programme for Research and Training in Tropical Diseases (TDR): the EMRO/DCD/TDR Small Grants Scheme for Operational Research in Tropical and Communicable Diseases.

We also gratefully acknowledge the scientific support of Professor R. Harback and his colleagues at the Natural History Museum for training opportunities and sequencing facilities, and staff of the medical entomology group of Tehran University of Medical Sciences. 


\section{References}

1. White GB. Systematic reappraisal of the Anopheles maculipennis complex. Mosquito systematics, 1978, 10:13-44.

2. Manouchehri AV, Zaim M, Emadi AM. A review of malaria in Iran, 1975-90. Journal of the American Mosquito Control Association, 1992, 4:381-5.

3. Kitzmiller JB, Frizzi G, Baker RH. Evolution and speciation within the maculipennis complex of the genus Anopheles. In: Wright JW, Pal R, eds. Genetics of insect vectors of disease. London, Elsevier, 1967:151-210.

4. Marinucci M et al. Phylogenetic relationships of seven Palaearctic members of the maculipennis complex inferred from ITS2 sequence data. Insect molecular biology, 1999, 8:469-80.

5. Linton YM, Samanidou-Voyadjoglou A, Harbach RE. Ribosomal ITS2 sequence data for Anopheles maculipennis and An. messeae in northern Greece, with a critical assessment of previously published sequences. Insect molecular biology, 2002, 11:379-83.

6. Proft J, Maier WK, Kampen H. Identification of six sibling species of the Anopheles maculipennis complex (Diptera: Culicidae) by a polymerase chain reaction assay. Parasitology research, 1999, 85(10):837-43.

7. Dow RP. Notes on Iranian mosquitoes. American journal of tropical medicine and hygiene, 1953, 2:683-95.

8. Faghih MA. Malarialogy and malaria eradication. Tehran, Tehran University of Medical Sciences Publishing, 1969: 1257.

9. Moemeni M. Study on the Anopheles maculipennis complex in north (Gilan and Mazanderan provinces) of Iran and the susceptibility of Mazanderan's maculipennis species to insecticides [thesis]. Tehran, Tehran University of Medical Sciences, 1991:177.

10. Saebi ME. Morphological identification of anopheline larvae and geographical distribution of anopheline mosquitoes of Iran [thesis]. Tehran, Tehran University of Medical Sciences, 1969:193.

11. Zahar AR. Review of the ecology of malaria vectors in the WHO Eastern Mediterranean Region. Bulletin of the World Health Organization, 1974, 50:427-40.

12. Bruce-Chwatt LJ, de Zulueta J. The rise and fall of malaria in Europe. Oxford, Oxford University Press, 1980.

13. Shahgudian ER. A key to the anophelines of Iran. Acta medica Iranica, 1960, 3:38-48.

14. Balinger-Crabtree ME, Black WC, Miller BR. Use of genetic polymorphisms detected by the random amplified polymorphic DNA polymerase chain reaction (RAPD-PCR) for differentiation and identification of Aedes aegypti subpecies and populations. American journal of tropical medicine and hygiene, 1992, 47:893-901.

15. Collins $\mathrm{FH}$, Paskewitz SM. A review of the use of ribosomal DNA (rDNA) to differentiate among cryptic Anopheles species. Insect molecular biology, 1996, 5:1-9.

16. Thompson JD et al. The CLUSTAL_X windows interface: flexible strategies for multiple sequence alignment aided by quality analysis tools. Nucleic acids research, 1997: 24:4876-82.

17. Cornel AJ, Porter $\mathrm{CH}$, Collins FH. Polymerase chain reaction species diagnostic assay for Anopheles quadrimaculatus cryptic species (Diptera: Culicidae) based on ribosomal DNA ITS2 sequences. Journal of medical entomology, 1996, 33:109-16.

المجلة الصحية لشرق المتوسط، منظمة الصحة العالمية، المجلد التاسع، العدد ؟، ب... 
18. Bullini L, Coluzzi M. Electrophoretic studies on gene-enzyme systems in mosquitoes (Diptera, Culicidae). Parasitologia, 1973, 15:221-48.

19. Manouchehri AV, Zaim M, Emadi AM. A review of malaria in Iran, 1975-90. Journal of the American Mosquito Control Association, 1992, 4:381-5.

20. Yaghoobi-Ershadi MR, Namazi J, Piazak N. Bionomic of Anopheles sacharovi in Ardebil Province, north-western Iran during a larval control program. Acta tropica, 2001,78:207-15.

21. Zaim M. Malaria control in Iran-present and future. Journal of the American Mos- quito Control Association, 1987, 3:3926.

22. Vatandoost $\mathrm{H}$ et al. Factors are involved in remerging of malaria in border line of Iran, Armenia, Azerbaijan, and Turkey. In: Proceedings of the Joint International Tropical Medicine Meeting 2002. Bangkok: SEAMEO Regional Tropical Medicine and Public Health Network, 2003: Southeast Asian journal of tropical medicine and public health; 34(suppl. 2) (poster presentation).

\section{Correction}

Correlates of unintended pregnancy in Beheira governorate, Egypt. R.M. Youssef, I.I. Moubarak, Y.A. Gaffer and H.Y. Atta. Eastern Mediterranean Health Journal, 2002, Vol. 8 Nos 4/5, pages 521-36. In the abstract: “. ...47.1\% of all women used no contraception...” should read:

“...47.1\% of women who reported unintended pregnancy were not using contraception...”

Table 1 title should read:

"Table 1 Pregnancy intention status in relation to social background of 880 women in Beheira governorate, Egypt”

المجلة الصحية لشرق المتوسط، منظمة الصحة العالمية، المجلد التاسع، العدد ع، ب... 